\title{
Erratum, Chaplin-Kramer et al. 2011. Rangelands 33(3): 33-41
}

An error occurred in the analysis that resulted in five counties being miscoded. Correcting this error revealed that Stanislaus and Ventura counties had much higher pollination service value provided by wild pollinators per pixel $\left(\mathrm{PS}_{\mathrm{Wi}}\right)$ and Tulare County had much lower values than previously calculated (Fig. 3). Supplemental Table 3 has been corrected online. Recalculating the statewide value results in a $\mathrm{PS}_{\mathrm{W}}$ of between $\$ 889$ million and $\$ 2.2$ billion, a 5-8\% reduction from our original calculation (Table 1). $\mathrm{PS}_{\mathrm{W}}$ still accounts for $34-36 \%$ of the total value of pollination services $\left(\mathrm{PS}_{\mathrm{T}}\right)$.
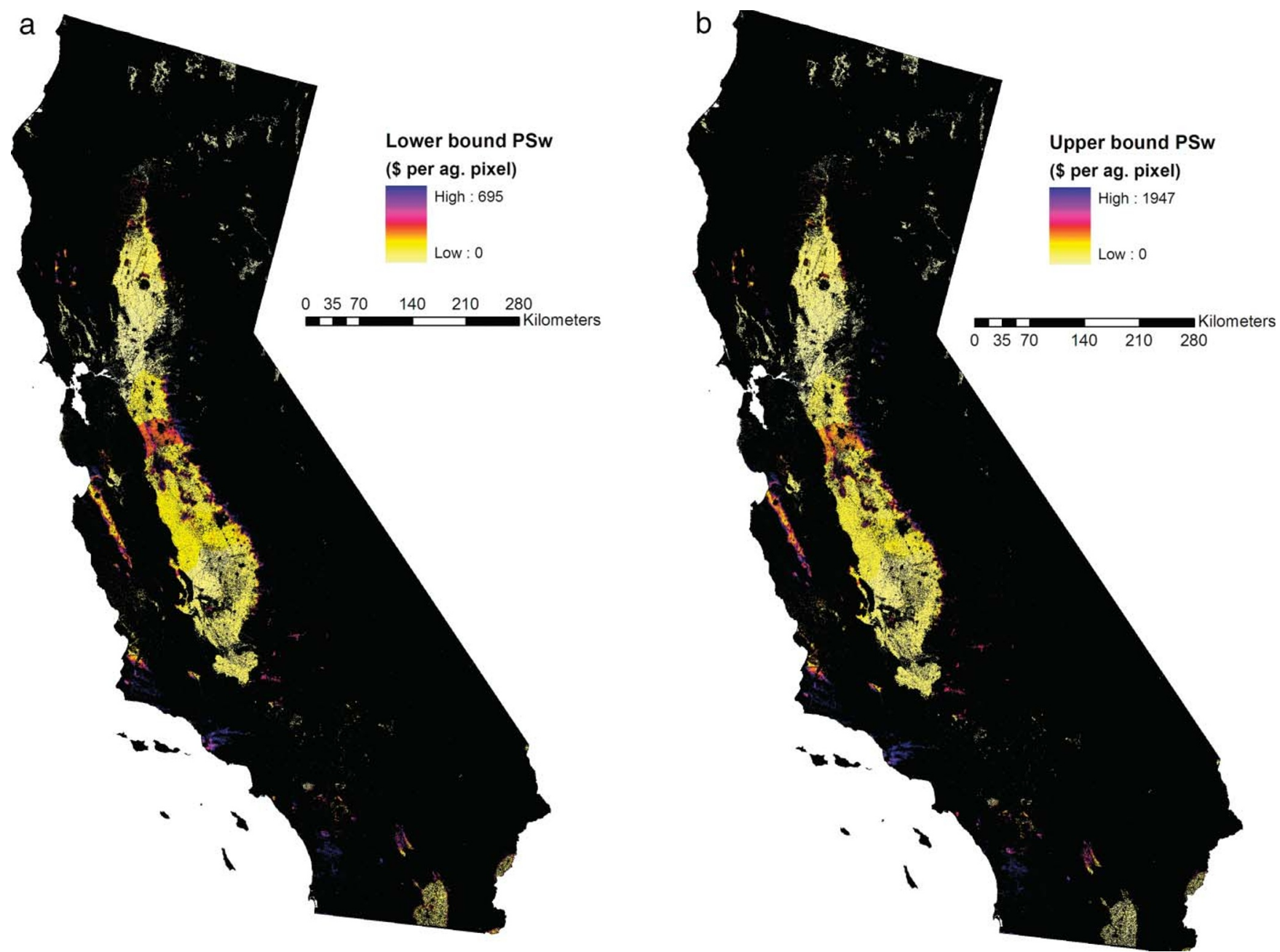

Figure 3. Map of pollination service value provided by wild pollinators per pixel $\left(P S_{w_{i}}\right)$ for the (a) lowest (lower-bound dependence estimate with only "yes" pollinator habitat) and (b) highest (upper-bound dependence estimate with "yes" and "yes-maybe" pollinator habitats) scenarios. The main difference between scenarios is not where areas of high value occur, but the magnitude of that value (shown on scales inset at right of map). Values are shown in 2007 dollars per pixel of agricultural land.

Table 1. The four scenarios for pollination service value from wild pollinators (PSW), in millions of 2007 dollars

\begin{tabular}{|l|c|c|c|}
\hline Bound & $\begin{array}{c}\text { Dependency } \\
\text { estimate }\end{array}$ & $\begin{array}{c}\text { Bee-relevant } \\
\text { habitat }\end{array}$ & PS $_{\mathbf{w}}$ (millions) \\
\hline Lowest & Lower & Yes & 889.45 \\
\hline Mid-Low & Lower & Yes-maybe & 895.45 \\
\hline Mid-High & Upper & Yes & 2190.04 \\
\hline Highest & Upper & Yes-maybe & 2204.55 \\
\hline
\end{tabular}

